\title{
Oxidative stability of cod liver oil in the presence of herring roe phospholipids
}

\author{
Liang, Peng; Akoh, Casimir C.; W. K. Diehl, Bernd; Jacobsen, Charlotte
}

Published in:

Food Chemistry

Link to article, DOI:

10.1016/j.foodchem.2019.125868

Publication date:

2020

Document Version

Peer reviewed version

Link back to DTU Orbit

Citation (APA):

Liang, P., Akoh, C. C., W. K. Diehl, B., \& Jacobsen, C. (2020). Oxidative stability of cod liver oil in the presence of herring roe phospholipids. Food Chemistry, 310, [125868]. https://doi.org/10.1016/j.foodchem.2019.125868

\section{General rights}

Copyright and moral rights for the publications made accessible in the public portal are retained by the authors and/or other copyright owners and it is a condition of accessing publications that users recognise and abide by the legal requirements associated with these rights.

- Users may download and print one copy of any publication from the public portal for the purpose of private study or research.

- You may not further distribute the material or use it for any profit-making activity or commercial gain

- You may freely distribute the URL identifying the publication in the public portal

If you believe that this document breaches copyright please contact us providing details, and we will remove access to the work immediately and investigate your claim 


\section{Journal Pre-proofs}

Oxidative stability of cod liver oil in the presence of herring roe phospholipids

Peng Liang, Casimir C. Akoh, Bernd W. K. Diehl, Charlotte Jacobsen

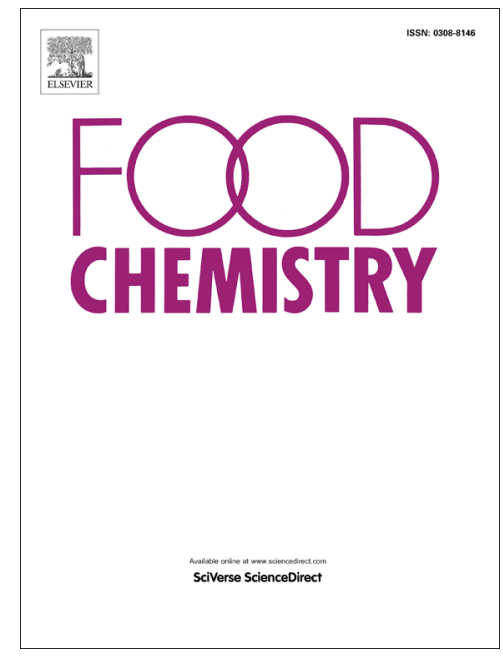

PII: $\quad$ S0308-8146(19)32004-7

DOI: $\quad$ https://doi.org/10.1016/j.foodchem.2019.125868

Reference: $\quad$ FOCH 125868

To appear in: $\quad$ Food Chemistry

Received Date: $\quad 17$ June 2019

Revised Date: $\quad 13$ October 2019

Accepted Date: $\quad 5$ November 2019

Please cite this article as: Liang, P., Akoh, C.C., W. K. Diehl, B., Jacobsen, C., Oxidative stability of cod liver oil in the presence of herring roe phospholipids, Food Chemistry (2019), doi: https://doi.org/10.1016/j.foodchem. 2019.125868

This is a PDF file of an article that has undergone enhancements after acceptance, such as the addition of a cover page and metadata, and formatting for readability, but it is not yet the definitive version of record. This version will undergo additional copyediting, typesetting and review before it is published in its final form, but we are providing this version to give early visibility of the article. Please note that, during the production process, errors may be discovered which could affect the content, and all legal disclaimers that apply to the journal pertain.

(C) 2019 Published by Elsevier Ltd. 


\section{Oxidative stability of cod liver oil in the presence of herring roe phospholipids}

Peng Liang a,d Casimir C. Akoh ${ }^{b}$, Bernd W. K. Diehl ${ }^{\text {c }}$, Charlotte Jacobsen ${ }^{\mathrm{d} *}$

${ }^{a}$ College of Food Science, Fujian Agriculture and Forestry University, 15 Shangxiadian Road, Fuzhou 350002, Fujian, China

${ }^{\text {bDepartment }}$ of Food Science \& Technology, University of Georgia, 30602 Athens, GA, USA

'Spectral Service AG, Emil-Hoffmann-Straße 33, D-50996 Köln, Germany

${ }^{\mathrm{d}}$ Division of Food Technology, National Food Institute (DTU Food), Technical University of Denmark, Building 204, Kemitorvet, DK 2800 Kgs Lyngby, Denmark

*Correspondence should be addressed to Charlotte Jacobsen (chja@food.dtu.dk), Division of Food Technology, National Food Institute (DTU Food), Technical University of Denmark, DK 2800 Kgs Lyngby, Denmark.

*Phone: +45 45252559. 


\section{Abstract}

2 The aim of this research was to investigate the effect of herring roe phospholipids

3 (PLs) on the oxidative stability of cod liver oil during storage. The effect of PLs on

4 the oxidative stability of cod liver oil was assessed in terms of peroxide value, free

5 fatty acids, secondary oxidation products and pyrrolisation. The results show that the

6 PV was lower in cod liver oil containing PLs $(P<0.05)$ than in the control without

7 PLs. Benzaldehyde, 2,5-dimethylpyrazine, 2-methyl-2-pentenal, 1-penten-3-ol and

8 3-methylbutanal were the main volatiles. In addition, significant pyrrolisation was

9 observed after 28 days when PLs were added to cod liver oil. The results suggested

10 that cod liver oil with dispersed PLs was oxidized during storage followed by

11 non-enzymatic browning reactions. The findings indicated that the ratio between

12 pyrroles formed and $\alpha$-tocopherol may influence the formation of new peroxides and

13 secondary oxidation products.

14 Keywords: marine phospholipids, oxidation, cod liver oil, non-enzymatic browning 15 reactions, strecker aldehydes. 


\section{Introduction}

Marine phospholipids (PLs) have received much attention by researchers due to their high content of polyunsaturated fatty acids (PUFAs), especially docosasahexaenoic acid (DHA) and eicosapentaenoic acid (EPA) (Belhaj, Arab-Tehrany, \& Linder, 2010). Marine PLs are naturally present in high concentration in fish heads (Gbogouri, Linder, Fanni, \& Parmentier, 2006), fish roe (Shirai, Higuchi, \& Suzuki, 2006) and krill oil (Burri, Hoem, Banni, \& Berge, 2012) with different fatty acid compositions. Many studies have shown that marine PLs have better oxidative stability than marine triacylglycerol (TAG) available from fish oil due to (a) their tight intermolecular packing conformation with the PUFA at the sn-2 position of PLs and (b) a synergistic effect of PLs on the antioxidant activity of $\alpha$-tocopherol. In addition, pyrroles formed from non-enzymatic browning reactions between oxidized PLs/amino acids and fatty acid oxidation products in slightly oxidized marine PLs have protective effects against oxidation (Lu, Nielsen, Baron, Diehl, \& Jacobsen, 2012).

Numerous studies have shown that natural PLs possess antioxidant activity. Hudson and Mahgoub (1981) reported that PLs from eggs were effective antioxidants in lard. Saito and Ishihara (1997) reported that phosphatidylethanolamine (PE) and phosphatidylcholine (PC) were good antioxidants in a sardine oil system. King et al. (1992) showed that the more egg yolk phosphatidylcholine (PC) added to salmon oil, the higher the oxidative stability obtained. They suggested that Maillard-type reaction products may have improved the oxidative stability of PL-supplemented fish oils.

Marine PLs contain higher amount of PUFAs compared to PLs from egg and soybean and may therefore be more susceptible to lipid oxidation than these PL 
sources. Despite their polyunsaturated nature, marine PLs may still provide antioxidative effects when added to other lipids. Belhaj, Arab-Tehrany, \& Linder (2010) evaluated the oxidative stability of salmon oil added with marine PC. Their results indicated that when marine PC was added as an emulsifier in salmon oil, it could increase the stability of salmon oil via its antioxidant activity despite an increase in long-chain PUFAs, especially with DHA due to addition of marine PC.

Moreover, the effect of temperature on lipid oxidation and non-enzymatic browning reactions in krill oil (rich in marine PLs) were investigated upon storage (Lu, Bruheim, Haugsgjerd, \& Jacobsen, 2014) The authors suggested that the formation of pyrroles might help to protect the krill oil against lipid oxidation. These antioxidative compounds were formed from non-enzymatic browning reactions between the primary amine group of PE or amino acids with the lipid oxidation products in marine PLs (Lu, Nielsen, Baron, Diehl, \& Jacobsen, 2013; Lu, Nielsen, Baron, \& Jacobsen, 2012).

Herring roe is an underutilized source of marine PLs. Approximately, 600,000 t herring are caught in Norway per year, but only a small amount of herring roe is consumed by humans. Thirty percent of the lipids in herring roe are marine PLs of which most are in the form of PC (75\%) (Bjørndal, Strand, Gjerde, Bohov, Svardal, Diehl, et al., 2014). Besides, the total EPA and DHA constituted more than $35 \%$ of total fatty acids. Oxidative stability of herring roe lipids was found to be higher than fish oils prepared from sardine and tuna (Moriya, Kuniminato, Hosokawa, Fukunaga, Nishiyama, \& Miyashita, 2007). The authors suggested that the higher oxidative stabilities of herring roe lipids would be mainly due to the presence of PLs.

To the best of our knowledge, the oxidative stability of cod liver oil with purified marine PLs from herring roe added has not been studied previously. The main 
objective of the present study was to investigate the effect of herring roe PLs on lipid oxidation of cod liver oil upon storage. The secondary objective is to investigate the non-enzymatic browning reactions in cod liver oil with herring roe PLs added upon storage. This is the first time the storage stability of cod liver oil with herring roe PLs added has been studied. Herring roe PLs were purified by acetone precipitation from herring roe oil to eliminate the effect of other factors on lipid oxidation, such as content of TAG, antioxidants or other residues that might be present in marine PLs.

\section{Materials and methods}

\subsection{Materials}

Herring roe oil was kindly provided by Novastell (Etrépagny, France). Commercial cod liver oil was obtained from Maritex A/S, subsidiary of TINE, BA (Sortland, Norway) without addition of antioxidant. The peroxide value (PV) of cod liver oil was $<0.1$ mequiv $/ \mathrm{kg}$, free fatty acids content (FFA) was $0.10 \%$. Contents of $\alpha$-, $\gamma$-, and $\delta$-tocopherol were $141 \pm 9,0 \pm 0,95 \pm 5,42 \pm 2 \mu \mathrm{g}$ toc/g oil, respectively. Herring roe oil was stored at $-40^{\circ} \mathrm{C}$ until use. The fatty acid composition of cod liver oil was as follows (\%, w/w): $8.90 \%$ palmitic acid (C16:0), 8.20\% pamitoleic acid (C16:1n-7), 1.86\% stearic acid (C18:0), 16.0\% oleic acid (C18:1n-9), 5.16\% vaccenic acid (C18:1n-7), 1.79\% linoleic acid (C18:2n-6), 0.84\% a-linolenic acid (C18:3n-3), $11.59 \%$ gadoleic acid (C20:1n-11), 9.27\% eicosapentaenoic acid (C20:5n-3), 6.06\% cetoleic acid (C22:1n-11), 11.64\% docosahexaenoic acid (C22:6n-3) and 7.78\% others.

\subsection{Methods}

2.2.1 Purification of phospholipids (PLs) from herring roe oil by acetone precipitation

$$
\text { PLs were isolated from herring roe oil by using acetone precipitation as }
$$


described by Mozuraityte and coworkers (2007) and Liang et al. (2017) with a few modifications. Briefly, $100 \mathrm{~g}$ herring roe oil was dissolved in $200 \mathrm{~mL}$ chloroform. This solution was then poured into $1000 \mathrm{~mL}$ of acetone under vigorous stirring at room temperature without light for $30 \mathrm{~min}$. Afterwards, the mixed solution was kept at $-18{ }^{\circ} \mathrm{C}$ overnight to allow PLs precipitation. The acetone was decanted and the PLs precipitates were redissolved in chloroform. The isolation step was repeated twice. The purified PLs were dried under nitrogen for $1 \mathrm{~h}$ to evaporate the acetone and chloroform.

\subsubsection{Determination of phospholipids classes by ${ }^{31} P$ NMR}

The classes of PLs were determined through ${ }^{31} \mathrm{P}$ NMR by Spectral Service GmbH (Cologne, Germany) using the same method as in our previous study (Lu, Nielsen, Baron, Diehl, and Jacobsen, 2012). See also data provided as supplementary material.- However, the The measurement was performed only once due to limited

\section{amount of sample material available.}

\subsubsection{Preparation of cod liver oil with different levels of PLs dispersion}

Five different formulations of PLs dispersion in cod liver oil were prepared with different levels of purified PLs (as shown in Table 1). To avoid the effect of tocopherol on the oxidative stability of cod liver oil, it was removed from PLs during acetone purification. Therefore, the oxidation of cod liver oil only depended on the effect of PLs and the synergism between tocopherol (from cod liver oil) and PLs.

\subsubsection{Oxidative stability determination}

The cod liver oil with different levels of PLs was incubated at $40{ }^{\circ} \mathrm{C}$ in darkness, exposed to air for up to 28 days and were stirred at regular intervals. For each type of cod liver oil, a beaker with $25.0 \mathrm{~g}$ of oil containing PLs were prepared. The experiment was performed in triplicate. Samples were taken from the same beaker on 
116 day $0,7,21$, and 28 . Samples were flushed with nitrogen and stored at $-20^{\circ} \mathrm{C}$ in

117 refrigerator until analysis, and the maximum storage time for the samples before

118 analysis should bewas -less than 10 days.

119 2.2.5 Determination of peroxide value (PV) and free fatty acids (FFA) of herring roe 120 oil and purified PLs

121 PV was determined in herring roe oil and purified PLs using the colorimetric

122 ferric-thiocyanate method at $500 \mathrm{~nm}$ as described by Shantha and Decker (1994). FFA

123 was determined using the AOCS method $\mathrm{Ca} 5 \mathrm{a}-40$ (1998). The measurement was

124 performed in duplicate.

125

126

127

128

129

130

131

132

133

134

135

136

137

138

139

140

\subsubsection{Determination of tocopherol}

The tocopherol content was determined according to AOCS method Ce 8-89 (1989b). Approximately $0.05 \mathrm{~g}$ of herring roe oil and purified PLs were dissolved in heptane $(10 \mathrm{~mL})$ and from this, $1.0 \mathrm{~mL}$ samples were analyzed by HPLC-FLD (Agilent 1100 series, Agilent Technologies, Santa Clara, CA) on a Water Spherisorb (R) $3 \mu \mathrm{m}$ silica column $(4.6 \times 150 \mathrm{~mm})$. The mobile phase consisted of heptane: isopropanol $(100: 0.4, \mathrm{v} / \mathrm{v})$. The flow rate was $1 \mathrm{~mL} / \mathrm{min}$. Tocopherols were detected by fluorescence (FLD) detector at $290 \mathrm{~nm}$ excitation and emission at $330 \mathrm{~nm}$. The determination was repeated twice and quantified by authentic standards.

\subsubsection{Determination of fatty acid composition of herring roe oil and purified PLs}

The fatty acid composition was determined according to AOCS Ce 2-66 (2000) with a minor modification. In detail, 30-60 mg of herring roe oil and purified PLs were weighed into vials, respectively. To each sample, $100 \mathrm{~mL}$ of internal standard (2\%, w/v, C23:0 in heptane), $200 \mathrm{~mL}$ heptane with $0.01 \%$ BHT, and $100 \mathrm{~mL}$ of toluene were added and mixed. Afterwards, $1 \mathrm{~mL}$ of methanolic $\mathrm{BF}_{3}$ (20\% solution) was added, and the methylation glass was sealed with a Teflon cap and a screw lid. 
141 The mixture was vortexed for $10 \mathrm{~s}$ and placed into a microwave oven (Multiwave

1423000 SOLV, Anton Paar, Graz, Austria). The conditions of the microwave for

143 methylation was 5 min at $100{ }^{\circ} \mathrm{C}$ with a power of $500 \mathrm{~W}$ followed by cooling $10 \mathrm{~min}$.

144 Next, $1 \mathrm{~mL}$ of saturated $\mathrm{NaCl}$ solution and $0.7 \mathrm{~mL}$ of heptane were added and mixed

145 for $10 \mathrm{~s}$. Later, approximately $1 \mathrm{~mL}$ of upper layer of heptane was transferred to a GC

146 vial for fatty acid composition analysis. During analysis, the fatty acid methyl esters

147 were separated by GC-FID (HP 5890 A, Hewlett Packard, Palo Alto, CA) with a

148 DB127-7012 column $(10 \mathrm{~m} \times$ ID $0.1 \mathrm{~mm} \times 0.1 \mathrm{~mm}$ film thickness $)$ using AOCS

149 Official Method Ce 1b-89 (AOCS, 1989a). Quantification of DHA, EPA and total n-3

150 polyunsaturated fatty acid (PUFAs) were conducted by using internal standard of

151 C23:0. The analysis was carried out in duplicate.

152

153

154

\subsubsection{Determination of volatiles by Dynamic Headspace GC-MS}

The procedure for volatiles determination was performed as described by Thomsen, et al. (2017), and Rørbæk (1994) with minor modifications. Approximately $1.0 \mathrm{~g}$ of sample was weighed and mixed with $30 \mathrm{mg}$ of internal standard solution (30 $\mu \mathrm{g} / \mathrm{g}$ of 4-methyl-1-pentanol in rapeseed oil). The volatiles were collected on Tenax ${ }^{\circledR}$ tubes (Gerstel, $\mathrm{GmbH} \& \mathrm{Co} . \mathrm{KG}$ ) for $30 \mathrm{~min}$ at $45^{\circ} \mathrm{C}$ with a nitrogen flow of 150 $\mathrm{mL} / \mathrm{min}$. The collected volatiles were desorbed by using an automatic thermal desorber (ATD-400, PerkinElmer, Norwalk, CT, USA) at $220^{\circ} \mathrm{C}$ combined with Agilent 5890 IIA model (Palo Alto, CA, USA) GC connected to a MS HP 5972 mass selective detector. The initial oven temperature was $35^{\circ} \mathrm{C}$ for $3 \mathrm{~min}$, with increment at $3.0^{\circ} \mathrm{C} / \mathrm{min}$ to $140^{\circ} \mathrm{C}$, and increment at $5.0^{\circ} \mathrm{C} / \mathrm{min}$ to $170^{\circ} \mathrm{C}$, then increment at 10.0 ${ }^{\circ} \mathrm{C} / \mathrm{min}$ to $240^{\circ} \mathrm{C}$, where it was held for $8 \mathrm{~min}$. Measurements were made in triplicate in each sample. The individual compounds were confirmed by mass-spectrometry (HP 5973 inert mass-selective detector, Agilent Technologies, USA; Electron 
ionization mode, $70 \mathrm{eV}$, mass to charge ratio scan between 30 and 250).

\subsubsection{Determination of pyrroles content}

The pyrroles content in cod liver oil containing different levels of PLs were determined according to Lu et al. (2012). Approximately $0.3 \mathrm{~g}$ of sample was weighed and $6 \mathrm{~mL}$ of chloroform-methanol (2:1) was added followed by addition of $2 \mathrm{~mL}$ of distilled water. After centrifugation $(2500 \mathrm{rpm})$, the chloroform phase was analyzed for pyrroles content in duplicate. Pyrroles content were quantified using an authentic external standard [1-(4-methoxyphenyl)-1H-pyrrole] (at $570 \mathrm{~nm}$ ). The pyrroles concentration are given as millimoles of 1-(4-methoxyphenyl)-1H-pyrrole per gram of sample.

Statistical analysis. The data were analyzed by analysis of variance (ANOVA) with Bonferroni's post-test for multiple comparisons using Minitab 16 statistical package (Minitab Inc., State College, PA). Significant differences were accepted at $\mathrm{p}$ $<0.05$.

\section{Result and discussion}

3.1 Formulation of cod liver oil with different levels of herring roe PLs

To evaluate the effect of herring roe PLs on the oxidation stability of cod liver oil, different levels of herring roe PLs was added to cod liver oil as shown in Table 1.

\subsection{Chemical composition of herring roe oil and purified phospholipids (PLs)}

In this work, PLs were purified from herring roe oil, which contained high amount of PLs (approximately 30\% of PLs in total herring roe oil) through acetone precipitation. Under this condition, the TAG and other nonpolar lipids were removed. The total PLs percentage increased from $33.75 \%$ to $72.30 \%$ (Table 2). In general, the purified PLs had higher content of PC, PI, LPC, LPE and APE than unpurified herring roe oil. The purified PLs also had a higher level of total LysoPLs (5.38\%) than 
unpurified sample (2.08\%), indicating some level of hydrolysis of PLs during purification. This phenomenon was also observed in our previous work ( $\mathrm{Lu}$, Nielsen, Baron, Diehl, \& Jacobsen, 2012). Also, the content of FFA increased when compared with untreated sample confirming that hydrolysis took place during purification.

As seen in Table 3, after purification, the PLs contained higher amounts of EPA and DHA when compared with the unpurified herring roe oil. The total content of EPA and DHA of purified PLs were $45.22 \%$ compared to $39.88 \%$ in unpurified herring roe oil. The DHA and EPA level in purified PLs were 33.24\% and 11.98\%, respectively. Mozuraityte et al. (2007) determined the isolated PLs from the total lipid of cod roe by acetone precipitation method. They found that the isolated PLs contained $98 \pm 2 \%$ of PLs, traces of cholesterol, and unknown compounds. On average, the isolated PLs was rich in DHA with $26 \pm 9 \%$ and EPA with $11 \pm 2 \%$ of total fatty acids. In our study, the purified herring roe PLs contained higher levels of DHA, but lower levels of PL. Tocher et al. (1984) analyzed the fatty acids composition in seven different types of fish roes and reported that the DHA and EPA levels in herring roe were $31.4 \%$ and $13.7 \%$, respectively. Furthermore, the DHA level was higher than EPA level in different kinds of fish roe.

In addition, the peroxide value of herring roe oil was also determined before and after purification, and it was 0.62 mequiv $/ \mathrm{kg}$ and 0.64 mequiv $/ \mathrm{kg}$, respectively. The result suggests that the purification method did not affect the oxidation of herring roe oil.

\subsection{Storage experiment of cod liver oil/herring roe phospholipids dispersion}

\subsubsection{PV and FFA.}

As seen in Fig. 1 (a), at the beginning of storage, PV increased significantly with an increase in content of PLs. This phenomenon may be due to the removal of 
tocopherol in purified PL. However, the PV showed significantly lower $(\mathrm{P}<0.05)$ increment during storage after 21 days when FO with added PLs was compared with FO. This result may be due to the antioxidant activity of PLs, or due to faster decomposition and reaction to secondary and tertiary oxidation products when FO was replaced with herring roe PLs.

The proportion of FFA in purified PLs was significantly higher than herring roe oil after purification. Thus, the FFA in FO with PLs added increased with increasing levels of PL added (Fig. 1(b). As the storage proceeded, the content of FFA was slightly-increased slightly but significantly in FO with low levels of PLs added $(\mathrm{P}>$ $0.05)$, butwhereas it -increased more in significantly in FPL5 $(\mathrm{P}<0.05)$. This finding may due to the high content of FFA in FO with $50 \%$ of PLs added could indicate that lipases in herring roe PL were still active during storage, but further investigations are

\section{needed to confirm this hypothesis.}

\subsubsection{Secondary lipid oxidation products: volatiles}

In order to further study the oxidative stability of FO with PLs, the concentration of volatiles were measured during storage. Fig. 2 show the changes in benzaldehyde, 2,5-dimethylpyrazine, 2-methyl-2-pentenal, 1-penten-3-ol, and 3-methylbutanal. Benzaldehyde was detected in FPL1 FPL5 after 7 days incubation at $40^{\circ} \mathrm{C}$. In particular, the level of benzaldehyde in FPL5 was the highest one from 7 days to 28 days followed by FPL3>FPL1>FPL2>FPL4. Benzaldehyde was only observed in FO after 21 days storage. It was reported that benzaldehyde was strongly correlated with sensory properties of FO (Guillén, Carton, Salmeron, \& Casas, 2009), and Giogios et al. (2009) assumed that benzene compounds could be decomposition products of amino acid or sugars due to their low level in FO. As illustrated by benzaldehyde in

Fig. 2, lipid oxidation occurred in FO after 21 days storage, and the degradation of 
241 PLs may play a key role in producing more benzaldehyde in FO.

Furthermore, Fig.2 (B) showed an appreciable increase in pyrazines as demonstrated by the presence of 2,5-dimethylpyrazine-in this study. There was no 2,5-dimethylpyrazine in FO and FPL1. However, the content of 2,5-dimethylpyrazine was-increased with increasing content of herring roe PLs in FO, especially FPL5 was higher than other treatments. This finding demonstrated that herring roe PLs played an important role in producing pyrazines. The effect of thermal treatment towards pyrazines formation was also reported in other studies. For instance, $\mathrm{Lu}$ and co-workers reported that 2,5-dimethylpyrazine and 2-ethylpyridine increased during storage $(\mathrm{P}<0.05)$ in krill oil incubated at $40^{\circ} \mathrm{C}(\mathrm{Lu}$, Bruheim, Haugsgjerd, \& Jacobsen, 2014). In addition, Baek and Cadwallader reported that 2,5-dimethylpyrazine increased drastically after enzymatic hydrolysis of crayfish hydrolysate at $65^{\circ} \mathrm{C}$ (Baek \& Cadwallader, 1996). The formation mechanism of all those pyrazines, pyridines and their alkyl derivatives were discussed in detail in our previous work on non-enzymatic browning reactions in krill oil upon storage (Lu, Bruheim, Haugsgjerd, \& Jacobsen, 2014). The possible pathways may involve lipid oxidation followed by reaction of lipid oxidation products and amino acids in marine PLs. They are important reactants for pyrazines formation. Thus, marine PLs may produce pyrazine when added to FO due to lipid oxidation.

As shown in Fig. 2(C), the content of 2-methyl-2-pentenal was increased with an increase in the amount of PLs added to FO at day 0, and further increased during storage. 2-methyl-2-pentenal was suggested to be the major volatile Strecker aldehyde resulting from a reaction between secondary lipid oxidation products originating from (E,E)-2,-4-heptadienal with lysine (Zamora, Ríos, \& Hidalgo, 2010). Hence, the higher formation of 2-methyl-2-pentenal during storage with increasing content of 
herring roe PLs suggested that lipid oxidation followed by non-enzymatic browning reactions took place to a higher degree when higher amounts of herring roe PLs were present.

1-Penten-3-ol is a typical lipid oxidation product (Eymard, Baron, \& Jacobsen, 2009) and is formed from the decomposition of hydroperoxides of the omega- 3 fatty acids (Olsen, Vogt, Saarem, Greibrokk, \& Nilsson, 2005). Lu et al. (2014) compared the increment rate of 1-penten-3-ol from Day 0 to 7 (in area per day) during incubation of krill oil at $40^{\circ} \mathrm{C}$ and found a 3-fold increment of 1-penten-3-ol compared to $20^{\circ} \mathrm{C}$.

In this work, we also determined the compound of 1-penten-3-ol as the typical lipid oxidation product. As shown in Fig. 2(D), 1-penten-3-ol was observed in all samples after day 7 in this study. Therefore, lipid oxidation occurred in each sample from day 7. In particular, FO and FPL5 contained higher levels of 1-penten-3-ol when compared to other treatments after 28 days. Interestingly, the dramatic increase of 1-penten-3-ol in FO and FPL5 from day 21 was probably related to their high degree of unsaturation. Further research is however still needed to understand why the formation of 1-penten-3-ol changed so dramatically between FPL4 and FPL5.

As shown in Fig. 2(E), 3- $\underline{m M e t h y l b u t a n a l ~ w a s ~ o b s e r v e d ~ i n ~ a l l ~ s a m p l e s, ~ a n d ~}$ followed by FPL1 $>$ FPL2 $>$ FPL3 $>$ FPL4 $>$ FPL5. In the present study, 3-Mmethylbutanal increased with the increment of PLs in FO over 28 days of incubation at $40^{\circ} \mathrm{C}$. 3-Methylbutanal is a degradation product from amino acids, such as valine, isoleucine and leucine (Lu, Nielsen, Baron, Diehl, \& Jacobsen, 2013). It is formed from the reaction between these amino acids with tertiary lipid oxidation products, namely unsaturated epoxy keto fatty esters, epoxyalkenals, and hydroxyalkenals. The mechanism was discussed in detail by Lu et al.(2012). It is 
necessary to further understand the relationship between FO and PLs for forming 3-Mmethylbutanal during storage.

Taken together, our finding suggested that cod liver oil with dispersed herring roe PLs oxidized during storage, and non-enzymatic browning reactions also took place after oxidation reaction.

\subsubsection{Pyrrolisation}

In this study, pyrrolisation in FO containing different levels of herring roe PLs was investigated via measurement of hydrophobic pyrroles (Fig. 3), since the hydrophobic pyrroles contributed more to browning than hydrophilic ones (Hidalgo, Nogales, \& Zamora, 2005). No pyrroles was found in any sample at the beginning of storage, and no pyrroles were formed in FO during storage up to 28 days.

It was clear that the hydrophobic pyrroles increased with increasing herring roe PLs addition from FPL1 to FPL5 (Fig. 3) confirming the results obtained for pyrazines and Strecker aldehydes in Fig. 2. When comparing the concentrations of pyrroles in FPL4 and FPL5 (0.67 $\mathrm{mM}$ vs $2.45 \mathrm{mM}$ in FPL5), it is surprising that the content of pyrroles in FPL5 was more than twice as high as in FPL4 despite the fact that the content of marine PL in FPL5 was less than twice as high as in FPL4. Results from the analysis of pyrazines and 2-methyl-2-pentenal (Fig. 2) also suggested a much larger difference between FPL4 and FPL5 than what could be expected from differences in the content of marine PL in these samples. This may be related to the relatively lower content of tocopherol in FPL5 as asis also discussed below. Further studies are needed to explain this accelerating effect of the non-enzymatic browning reactions of increasing the content of marine PL from 20 to $33 \%$ of total lipids.

The presence of hydrophobic pyrroles might offer additional protection to FO against lipid oxidation. Based on the lower PV, the relative oxidative stability of FO 
containing PLs may be partly affected by the higher content of pyrroles. However, the PV of FPL5 was higher than other dispersions containing PLs. It can be speculated that this was due to the lower content of tocopherol in FPL5 compared with other treatments (FPL1-FPL4). It can be calculated that the content of $\alpha$-tocopherol in FO was $141 \mu \mathrm{g} / \mathrm{g}$, but $93.06 \mathrm{mg} / \mathrm{kg}$ in FPL5. As we mentioned before, the tocopherol in herring roe oil was removed during precipitation with cold acetone. It has been shown that the antioxidant activity of pyrroles can be improved by $\alpha$-tocopherol (Hidalgo, León \& Zamora, 2007; Lu, Nielsen, Baron, Diehl \& Jacobsen, 2012). Hence, the ratio between pyrroles and $\alpha$-tocopherol may have influenced the formation of peroxides and secondary oxidation products in FPL1-FPL5. This deserves further investigation.

\section{Conclusions}

The purified herring roe PLs contained high level of DHA, and the main component was PC, followed by PE. In addition, the present work evaluated the effect of purified herring roe PLs on the oxidation stability of FO during 28 days of storage at $40^{\circ} \mathrm{C}$. The results demonstrated that after 21 and 28 days PV was lower in FO containing purified PLs, and the FFA in FO with PLs added increased with FPL1 to FPL5. Furthermore, the concentration of volatiles, including benzaldehyde, 2,5-dimethylpyrazine, 2-methyl-2-pentenal, 1-penten-3-ol, and 3-methylbutanal were monitored to evaluate the formation of volatile oxidation and non-enzymatic reaction products. The results suggested that lipid oxidation was followed by non-enzymatic browning reactions. Furthermore, pyrroles, which may protect against formation of new peroxides, were formed. However, the ability of pyrroles to confer this protection may be influenced by the level of $\alpha$-tocopherol and pyrroles formed.

\section{AUTHOR INFORMATION}

\section{Corresponding Author}


*Phone: +45 452525 59. E-mail: chja@food.dtu.dk.

\section{$342 \quad$ Notes}

343 The authors declare no competing financial interest.

$344 \quad$ FUNDING

345 This work is supported by the National Natural Science Foundation of China (Grant

No. 31801465) and Outstanding Young Scientific Research Talent Program of Fujian

347 Agriculture and Forestry University (xjq20180).

\section{ACKNOWLEDGMENTS}

349 We thank Thierry COSTE (Novastell, France) for free marine phospholipid samples.

350 We also greatly appreciate Inge Holmberg and Thi Thu Trang Vu's kind help for the 351 volatiles and lipid chemical composition analysis.

\section{$352 \quad$ References}

AOCS.Official Method Ce 8-89. Determination of tocopherols and tocotrienols in vegetable oils and fats by HPLC. AOCS Press, Champaign, IL. USA. 1989b.

AOCS.Method Ca 5a-40: Free Fatty Acids. In: Firestone, D. (Eds.), Official Methods and Oil Chemists' Society Urbana, IL, USA. 

and Food Chemistry[J], 1996.44(10), 3262-3267.

Belhaj, N., Arab-Tehrany, E., \& Linder, M. Oxidative kinetics of salmon oil in bulk and in nanoemulsion stabilized by marine lecithin. Process Biochemistry[J], 2010.45(2), 187-195. Berge, R. K.Phospholipids from herring roe improve plasma lipids and glucose tolerance in healthy, young adults. Lipids in Health and Disease[J], 2014.13(1), 82.

Burri, L., Hoem, N., Banni, S., \& Berge, K.Marine omega-3 phospholipids: metabolism and biological activities. International Journal of Molecular Sciences[J], 2012.13(11), 15401-15419.

Eymard, S., Baron, C. P., \& Jacobsen, C.Oxidation of lipid and protein in horse mackerel (Trachurus trachurus) mince and washed minces during processing and storage. Food Chemistry[J],

Gbogouri, G. A., Linder, M., Fanni, J., \& Parmentier, M.Analysis of lipids extracted from salmon (Salmo salar) heads by commercial proteolytic enzymes. European Journal of Lipid Science and Technology[J], 2006.108(9), 766-775.

Giogios, I., Grigorakis, K., Nengas, I., Papasolomontos, S., Papaioannou, N., \& Alexis, M. N.Fatty acid composition and volatile compounds of selected marine oils and meals. Journal of the Science of Food and Agriculture[J], 2009.89(1), 88-100.

Guillén, M. D., Carton, I., Salmeron, J., \& Casas, C.Headspace composition of cod liver oil and its evolution in storage after opening. First evidence of the presence of toxic aldehydes. Food Chemistry[J], 2009.114(4), 1291-1300. 
Hidalgo, F. J., Nogales, F., \& Zamora, R.Changes produced in the antioxidative activity of phospholipids as a consequence of their oxidation. Journal of Agricultural and Food Chemistry[J], 2005.53(3), 659-662.

Hudson, B. J., \& Mahgoub, S. E.Synergism between phospholipids and naturallyoccurring antioxidants in leaf lipids. Journal of the Science of Food and Agriculture[J], 1981.32(2), 208-210.

King, M., Boyd, L., \& Sheldon, B.Antioxidant properties of individual phospholipids in a salmon oil model system. Journal of the American Oil Chemists Society[J], 1992.69(6), 545-551.

Liang, P., Cheng, X., Xu, Y., Cheng, W., \& Chen, L.Determination of fatty acid composition and phospholipid molecular species of large yellow croaker (Pseudosciaena crocea) roe from non-enzymatic browning reactions in krill oil upon storage. Food Chemistry[J], 2014.157,

Lu, F., Nielsen, N. S., Baron, C. P., Diehl, B., \& Jacobsen, C.Impact of primary amine group from

Lu, F., Nielsen, N. S., Baron, C. P., \& Jacobsen, C.Oxidative degradation and non-enzymatic browning aminophospholipids and amino acids on marine phospholipids stability: Non-enzymatic browning and lipid oxidation. Food Chemistry[J], 2013.141(2), 879-888. PL emulsions. Food Chemistry[J], 2012.135(4), 2887-2896. 
prepared from purified marine phospholipid and the role of $\alpha$-tocopherol. Journal of Agricultural and Food Chemistry[J], 2012.60(50), 12388-12396.

Lu, F. S. H., Nielsen, N. S., Baron, C. P., Diehl, B. W. K., \& Jacobsen, C.Oxidative Stability of Dispersions Prepared from Purified Marine Phospholipid and the Role of $\alpha$-Tocopherol. Journal of Agricultural \& Food Chemistry[J], 2012.60(50), 12388-12396.

Lu, F. S. H., Nielsen, N. S., Baron, C. P., Diehl, B. W. K., \& Jacobsen, C.Impact of primary amine group from aminophospholipids and amino acids on marine phospholipids stability: stability of salmon and herring roe lipids and their dietary effect on plasma cholesterol levels

Rørbæk, K. (1994). Oxidation and flavours in fish oil. Ph. D. thesis. Technological Laboratory Ministry of Fisheries and Center for Food Research, Technical University of Denmark, Lyngby.

Saito, H., \& Ishihara, K.Antioxidant activity and active sites of phospholipids as antioxidants. Journal of the American Oil Chemists' Society[J], 1997.74(12), 1531-1536. determination of perorlride values of food lipids. Journal of AOAC International[J], 
431 Shirai, N., Higuchi, T., \& Suzuki, H.Analysis of lipid classes and the fatty acid composition of the salted fish roe food products, Ikura, Tarako, Tobiko and Kazunoko. Food Chemistry[J], 2006.94(1), 61-67.

434

Thomsen, B., Horn, A., Hyldig, G., Taylor, R., Blenkiron, P., \& Jacobsen, C.Investigation of Lipid Oxidation in High-and Low-Lipid-Containing Topical Skin Formulations. Journal of the American Oil Chemists' Society[J], 2017.94(10), 1287-1300. European marine fish. Lipids[J], 1984.19(7), 492-499. 
443

444

445

446

447

448

449

450

451

452

453

454

455

456

457

458

459

460

\section{Figure captions}

Fig. 1 Measurement of PV and FFA in FO and FO with added levels of PLs during 28 days of storage at $40{ }^{\circ} \mathrm{C}$. Values are mean \pm standard deviation $(\mathrm{n}=3)$. (a) PV; (b)

FFA. Note: Letters in lower case indicate comparisons between values on the same day with different concentrations, and letters in upper case indicate comparisons between values of the same concentrations on different days. Note: FO, cod liver oil as control; FPL1, 2.5\% of PLs added in FO; FPL2, 10\% of PLs added in FO; FPL3, $20 \%$ of PLs added in FO; FPL4, 25\% of PLs added in FO; FPL5, 50\% of PLs added in FO. Values are the mean \pm standard deviation $(n=3)$.

Fig. 2 Measurement of benzaldehyde, 2,5-dimethylpyrazine, 2-methyl-2-pentenal, 1-penten-3-ol, 3-methylbutanal in FO and FO with added levels of PLs during 28 days of storage at $40^{\circ} \mathrm{C}$. Values are the mean \pm standard deviation $(n=3)$.

Fig. 3 Comparison of pyrroles in 50\% of PLs in FO (FML5) after 28 days of storage at $40{ }^{\circ} \mathrm{C}$. Values are the mean \pm standard deviation $(n=2)$. Note: Letters in lower case indicate comparisons between values on the same day with different concentrations of PLs. Note: FPL1, 2.5\% of PLs added in FO; FPL2, 10\% of PLs added in FO; FPL3, $20 \%$ of PLs added in FO; FPL4, 25\% of PLs added in FO; FPL5, 50\% of PLs added in FO. 
461 Tables:

462 Table 1. Experimental design for the cod liver oil containing herring roe PLs

463 Table 2. Composition of herring roe oil before and after acetone precipitation

464 Table 3. Fatty acid compositions of herring roe oil PLs before and after acetone 465 precipitation 
Fig. 1.
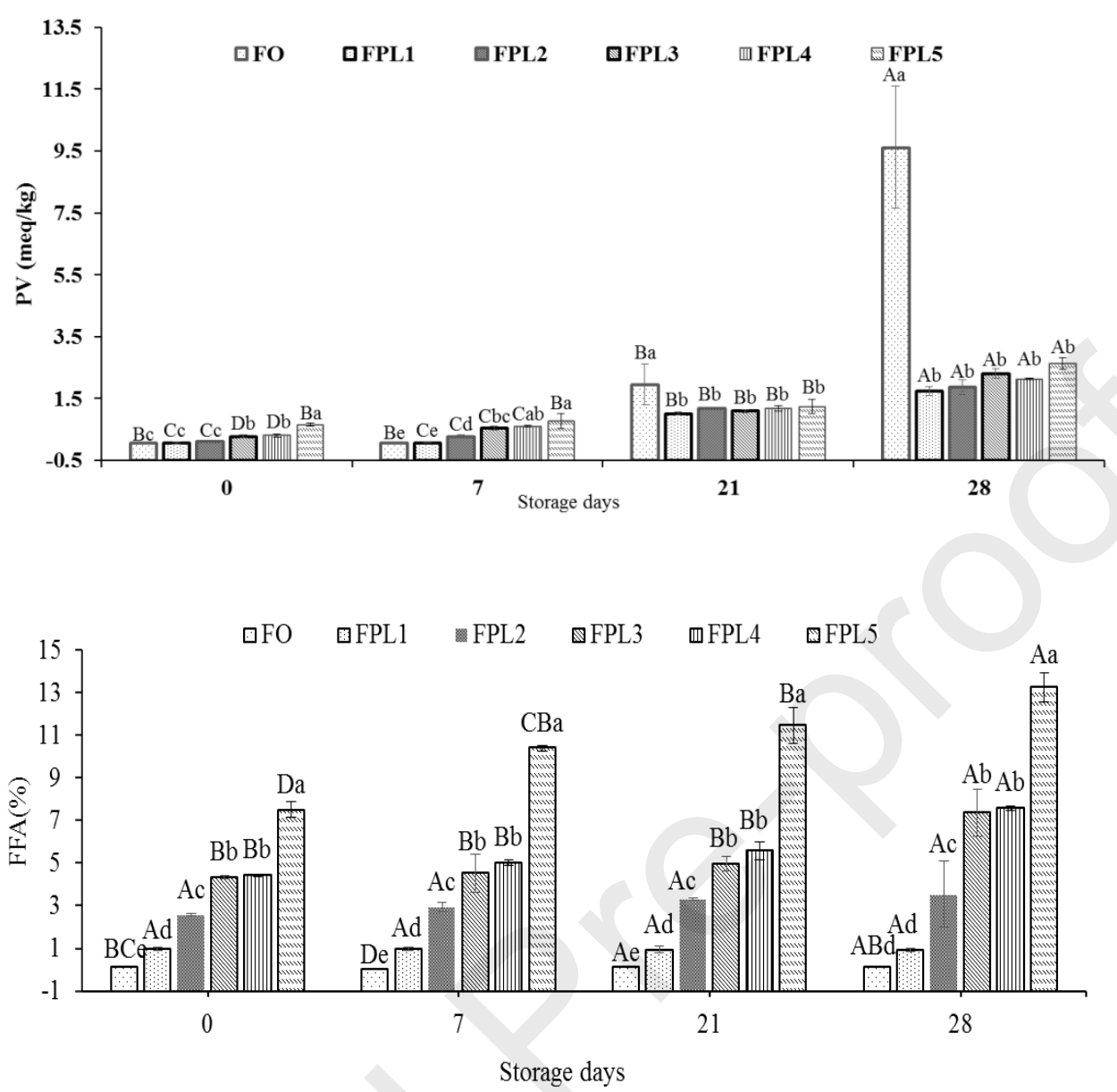
Fig. 2.
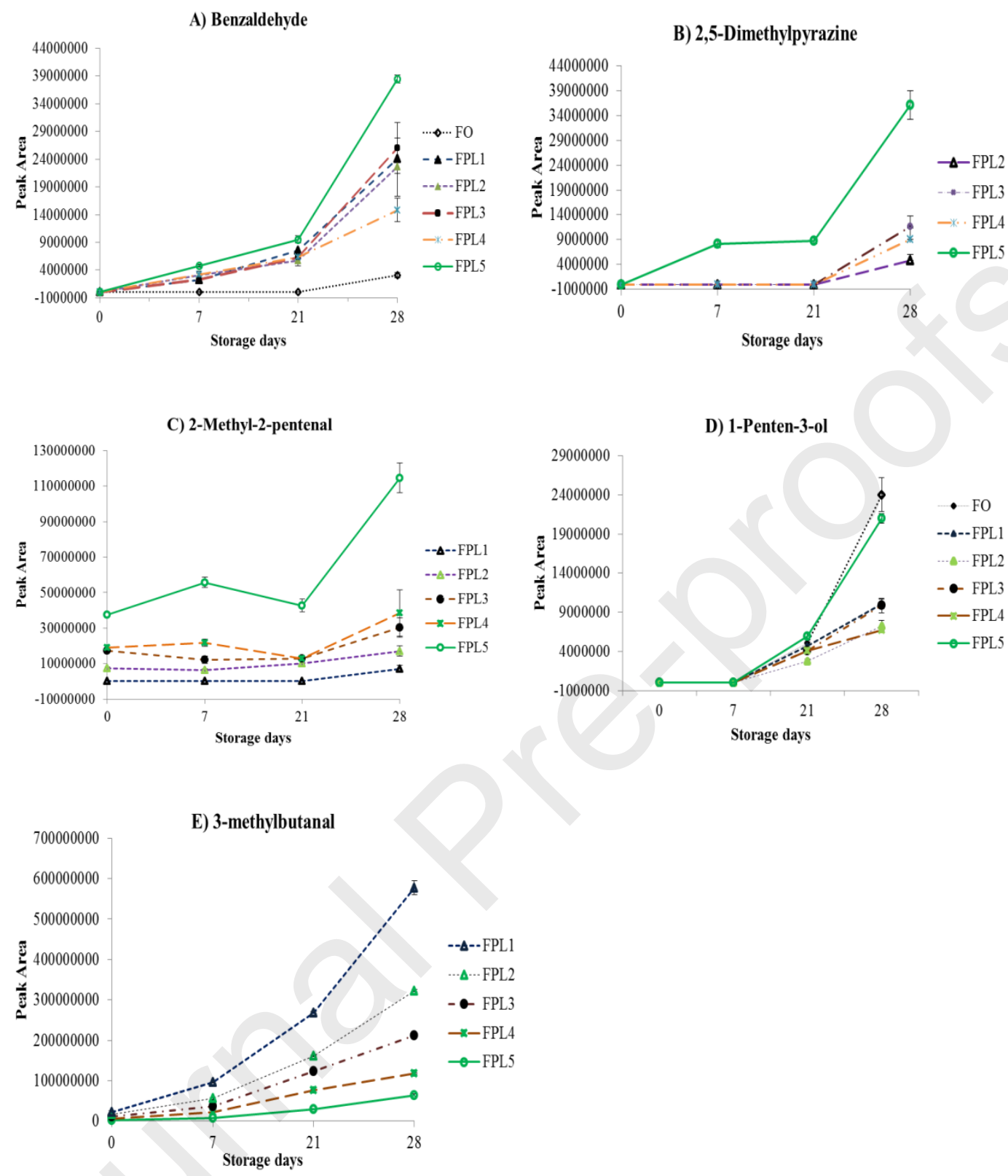
Fig. 3.

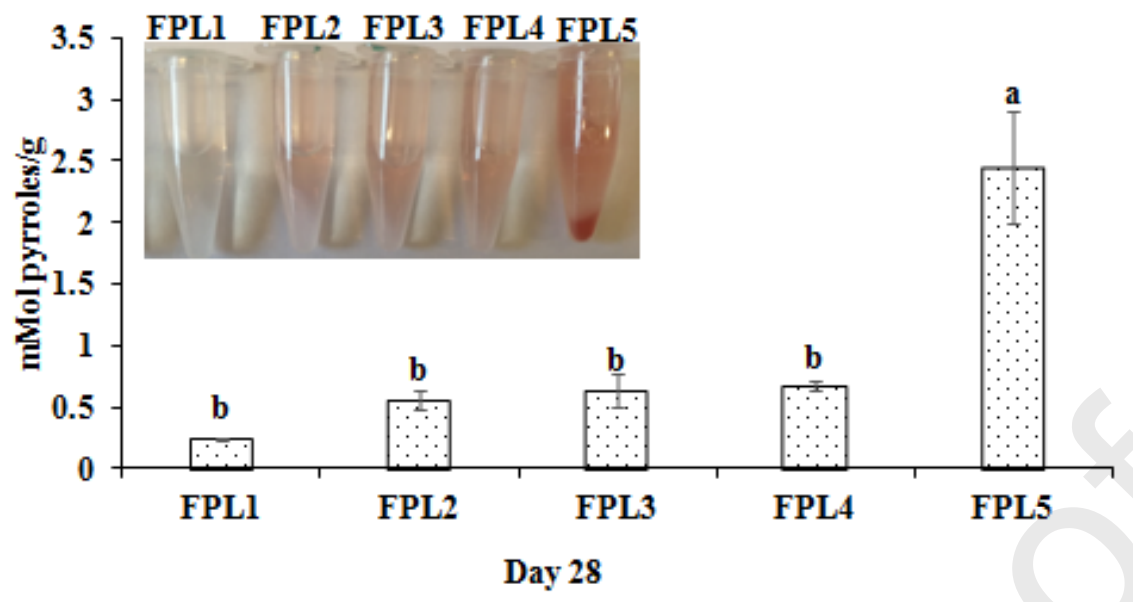


Table 1.

\begin{tabular}{|c|c|c|c|}
\hline items & $\begin{array}{c}\text { Cod liver oil } \\
\text { (g) }\end{array}$ & $\begin{array}{l}\text { Added PLs to cod liver oil } \\
\qquad(\mathrm{g})\end{array}$ & $\begin{array}{l}\text { PLs relative to cod liver oil } \\
\qquad(\%)\end{array}$ \\
\hline FO & 100.0 & 0.0 & 0.0 \\
\hline FPL1 & 97.56 & 2.44 & 2.50 \\
\hline FPL2 & 90.91 & 9.09 & 10.00 \\
\hline FPL3 & 83.33 & 16.67 & 20.00 \\
\hline FPL4 & 80.00 & 20.00 & 25.00 \\
\hline FPL5 & 66.67 & 33.33 & 50.00 \\
\hline
\end{tabular}

Note: FO, cod liver oil; FPL1, 2.5\% of PLs added in cod liver oil; FPL2, 10\% of PLs added in FO; FPL3, 20\% of PLs added in FO; FPL4, 25\% of PLs added in FO; FPL5, $50 \%$ of PLs added in FO. 
Table 2.

\begin{tabular}{|c|c|c|}
\hline & \multirow{2}{*}{$\begin{array}{l}\text { Before purification } \\
\text { herring roe oil }\end{array}$} & \multirow{2}{*}{$\begin{array}{l}\text { After purification } \\
\text { herring roe PLs }\end{array}$} \\
\hline & & \\
\hline Total phospholipids of total lipid (\%) & 33.75 & 72.30 \\
\hline Phosphatidylcholine (PC) of total PLs (\%) & 26.94 & 55.40 \\
\hline $\begin{array}{l}\text { Lysophosphatidylcholine (1-LPC) of total } \\
\text { PLs (\%) }\end{array}$ & 0.20 & 0.41 \\
\hline $\begin{array}{l}\text { Lysophosphatidylcholine (2-LPC) of total } \\
\text { PLs (\%) }\end{array}$ & 1.58 & 4.06 \\
\hline Phosphatidylinositol (PI) of total PLs (\%) & 0.87 & 2.44 \\
\hline $\begin{array}{l}\text { Phosphatidylethanolamine (PE) of total } \\
\text { PLs (\%) }\end{array}$ & 3.33 & 5.49 \\
\hline $\begin{array}{l}\text { Lysophosphatidyl ethanolamine of total } \\
\text { PLs (LPE) (\%) }\end{array}$ & 0.30 & 0.81 \\
\hline $\begin{array}{l}\text { Acylated phosphatidyl ethanolamine } \\
\text { (APE) of total PLs (\%) }\end{array}$ & ND & 0.61 \\
\hline Phosphatidate (PA) of total PLs (\%) & 0.18 & 0.40 \\
\hline $\begin{array}{l}\text { Lysobisphosphatidic acids (LPA) of total } \\
\text { PLs (\%) }\end{array}$ & ND & 0.10 \\
\hline Other phospholipids of total PLs (\%) & 0.34 & 2.63 \\
\hline Peroxide value (mequiv/kg) & $0.62 \pm 0.01$ & $0.64 \pm 0.03$ \\
\hline Free fatty acid $(\%)$ & $22.61 \pm 1.09$ & $31.37 \pm 6.43$ \\
\hline$\alpha$-Tocopherol (mg/kg) & $222 \pm 1.05$ & ND \\
\hline$\gamma$-Tocopherol (mg/kg) & $319 \pm 1.23$ & ND \\
\hline$\delta$-Tocopherol (mg/kg) & $112 \pm 0.74$ & ND \\
\hline
\end{tabular}

PLs=phospholipids

$\mathrm{ND}=$ not detected 
Table 3.

\begin{tabular}{|c|c|c|}
\hline & Herring roe oil (\% of total fatty acids) & $\begin{array}{l}\text { Herring roe PLs (\% of total } \\
\text { fatty acids) }\end{array}$ \\
\hline C14:0 & $2.28 \pm 0.10$ & $2.43 \pm 0.01$ \\
\hline C14:1 & $0.13 \pm 0.00$ & $0.15 \pm 0.00$ \\
\hline C15:0 & $0.46 \pm 0.03$ & $0.56 \pm 0.00$ \\
\hline C16:0 & $16.77 \pm 0.90$ & $23.18 \pm 0.90$ \\
\hline C16:1(n-7) & $2.92 \pm 0.02$ & $1.56 \pm 0.01$ \\
\hline C16:2(n-4) & $0.09 \pm 0.00$ & $0.06 \pm 0.00$ \\
\hline C16:3(n-4) & $0.64 \pm 0.00$ & $0.36 \pm 0.00$ \\
\hline $\mathrm{C} 17: 0$ & $0.20 \pm 0.00$ & $0.31 \pm 0.00$ \\
\hline $\mathrm{C} 17: 1$ & - & $0.20 \pm 0.00$ \\
\hline C16:4(n-3) & $0.07 \pm 0.00$ & $0.38 \pm 0.00$ \\
\hline C18:0 & $1.40 \pm 0.01$ & $2.86 \pm 0.02$ \\
\hline C18:1(n-9) & $4.24 \pm 0.10$ & $5.47 \pm 0.08$ \\
\hline C18:1(n-7) & $2.67 \pm 0.09$ & $3.52 \pm 0.04$ \\
\hline C18:2(n-6) & $0.20 \pm 0.00$ & $0.81 \pm 0.00$ \\
\hline $\mathrm{C} 18: 2(\mathrm{n}-4)$ & - & $0.06 \pm 0.00$ \\
\hline C18:3(n-6) & $0.13 \pm 0.00$ & $0.08 \pm 0.00$ \\
\hline C18:3(n-4) & . & $0.12 \pm 0.00$ \\
\hline C18:3(n-3) & $0.37 \pm 0.00$ & $0.32 \pm 0.00$ \\
\hline C18:4(n-3) & $0.59 \pm 0.00$ & $0.30 \pm 0.00$ \\
\hline C18:5(n-3) & $0.04 \pm 0.00$ & $0.05 \pm 0.00$ \\
\hline $\mathrm{C} 20: 0$ & - & $0.06 \pm 0.00$ \\
\hline C20:1(n-9, n-11) & - & $0.70 \pm 0.00$ \\
\hline C20:1(n-7) & $0.93 \pm 0.00$ & $0.73 \pm 0.00$ \\
\hline C20:2(n-6) & $0.07 \pm 0.00$ & $0.13 \pm 0.00$ \\
\hline$C 20: 3(n-6)$ & $0.06 \pm 0.00$ & $0.05 \pm 0.00$ \\
\hline C20:4(n-6) & $0.59 \pm 0.00$ & $0.86 \pm 0.00$ \\
\hline C20:3(n-3) & $0.16 \pm 0.00$ & $0.05 \pm 0.00$ \\
\hline $\mathrm{C} 20: 4(\mathrm{n}-3)$ & $0.76 \pm 0.00$ & $0.42 \pm 0.00$ \\
\hline \multirow{2}{*}{\multicolumn{3}{|c|}{$(n-3)$ EPA }} \\
\hline & & \\
\hline C22:1(n-11) & $0.03 \pm 0.00$ & $0.03 \pm 0.00$ \\
\hline C22:1(n-9) & $0.20 \pm 0.00$ & $0.37 \pm 0.00$ \\
\hline $\mathrm{C} 21: 5(\mathrm{n}-3)$ & $7.85 \pm 0.70$ & $0.16 \pm 0.00$ \\
\hline$C 22: 5(n-3)$ & $1.34 \pm 0.00$ & $0.99 \pm 0.00$ \\
\hline C22:6 & $\mathbf{2 9 . 5 1} \pm 1.20$ & 33.24 \pm 1.40 \\
\hline \multicolumn{3}{|l|}{ (n-3)DHA } \\
\hline $\mathrm{C} 24: 1(\mathrm{n}-9)$ & $1.69 \pm 0.00$ & - \\
\hline $\mathrm{C} 24: 0$ & $3.34 \pm 0.08$ & $1.02 \pm 0.00$ \\
\hline Others & $9.90 \pm 0.85$ & $6.43 \pm 0.04$ \\
\hline EPA + DHA & $\mathbf{3 9 . 8 8} \pm 1.70$ & $\mathbf{4 5 . 2 2} \pm 2.20$ \\
\hline$\Sigma \mathrm{SAFA}$ & $24.45 \pm 0.31$ & $30.42 \pm 0.93$ \\
\hline$\Sigma$ MUFA & $12.81 \pm 0.11$ & $12.73 \pm 0.13$ \\
\hline ¿PUFA & $52.84 \pm 2.40$ & $50.42 \pm 2.20$ \\
\hline
\end{tabular}

PLs=phospholipids

Values are means $\pm \mathrm{SD}, \mathrm{n}=2$.

\section{Highlights :}

- The effect of herring roe phospholipids on the oxidative stability of cod liver oil was investigated systematically. 
- Benzaldehyde, 2,5-dimethylpyrazine, 2-methyl-2-pentenal, 1-penten-3-ol and 3-methylbutanal were the main volatiles during storage at $40 \mathrm{oC}$.

- Significant pyrrolisation was observed after 28 days when herring roe phospholipids were added to cod liver oil.

- The cod liver oil with dispersed herring roe phospholipids was oxidized during storage followed by non-enzymatic browning reactions

\section{Declaration of interests}

$\bigotimes$ The authors declare that they have no known competing financial interests or personal relationships

that could have appeared to influence the work reported in this paper.

$\square$ The authors declare the following financial interests/personal relationships which may be considered

as potential competing interests 